\section{A twice-paired watershed experimental design to assess stacked practices through field-edge monitoring}

\author{
M.D. Tomer
}

\begin{abstract}
Field experiments that measure impacts of stacked practices are possible and can be aimed at combinations of practices that are most opportune across a watershed or landscape region. If we know watershed responses to conservation will only be observed over decades, we should be willing to invest in long-term, field-scale conservation research, especially knowing that results should improve our ability to use practices in combination. The data obtained from twice-paired watershed experiments could also help improve models and our capacity to confidently simulate approaches to use combined conservation practices for water quality improvement.
\end{abstract}

Key words: conservation effects assessment-edge-of-field monitoring-paired watershed experiments—-stacked practices

Field-edge monitoring provides a direct way to document conservation-practice effectiveness (Ball Coehlo et al. 2012; Reba et al. 2013; Sharpley et al. 2015; Smith et al. 2015). However field-scale assessments of conservation practice effects on water quality are difficult to undertake due to the costs and duration of monitoring. The paired watershed design (Loftis et al. 2001) requires paired observations that provide three to five years of pretreatment data before a selected conservation practice can be implemented and its assessment begin. This is why the paired watershed approach has been rarely applied to test agricultural practices, with relatively few examples available in the literature (Bishop et al. 2005; King et al. 2008). It may take years to accrue a monitoring record sufficient for statistical comparison of treated and nontreated fields, especially when extreme events occur and then need to be placed in a long-term context (Karlen et al. 2009; Tomer et al. 2016). Action agencies, under public pressure to obtain measureable environmental outcomes, cannot tenably explain that years of experimental data are needed to identify management actions of known, proven effectiveness. This deters investment in long-term research.
Yet, knowledge gaps afflicting resource management are perpetuated by avoiding long-term research (Hewlett 1971). Modeling can help fill this gap and support watershed planning, as shown by recent successful examples in the literature (Gebremichael et al. 2013; Brooks et al. 2015; Kalcic et al. 2015; Yang and Best 2015). However, decision-making based on modeling results carries risk, especially where long-term records needed for model calibration are not available. This increases model uncertainty, which should be considered when management actions are selected based on simulations of alternative watershed scenarios.

Paired field-edge experiments are not only costly and lengthy, but they are also limited to evaluation of a single conservation treatment. However, no single practice is likely to achieve water quality improvement goals in any agricultural watershed (Osmond et al. 2012). Combinations of practices that can be applied across a given landscape are needed to account for water quality tradeoffs or mitigate unintended consequences resulting from any single practice (Tomer et al. 2015). How can combinations of practices that can have the greatest effect at watershed scale be identified?
The combined effectiveness of conservation practices placed along flow paths from field to stream has been estimated by multiplication (Lazarus et al. 2014; Tomer et al. 2015). While reasonable, this has not been confirmed experimentally. Experimental designs that can provide data to support causal inferencing on water quality are lacking (Rissman and Carpenter 2015). Modeling approaches have been used to simulate the effectiveness of combined practices in a few situations (Kalcic et al. 2015), but extension requires consistent calibration data, which returns us to issues of data availability and sufficiency. The purpose of this editorial is to point out an approach to link stacked practices, edge-of-field monitoring, and modeling efforts in a way that can overcome the impasse between the need for better management and the need for better management to be based on our best available science. We know that it can take decades for water quality improvements from conservation action to be documented. Knowing this, we should be willing to invest in long-term research to support and improve conservation effectiveness in watersheds through use of combinations of practices.

The Inefficiency of Field-Scale Experiments Direct, field-scale conservation-effects assessments require data from two stations to assess the effectiveness of a single practice in one place. This is true whether an in-field or a field-edge (or "trap and treat") practice is being assessed. In-field practices, including nutrient management practices, no-tillage, cover crops, and rotations are best assessed by comparison to a similar field that is being farmed without that practice. "Before and after" monitoring approaches may require just one gage, but are less statistically robust than using the paired approach (Loftis et al. 2001). When evaluating field-edge practices, such as bioreactors, wetlands, etc., again two gages are needed to calculate practice performance by comparing inflows and outflows. Essentially, we need two gage stations to assess one practice. Neither paired-watershed approaches nor upstream-downstream comparisons can provide data about the interactive performance of combined practices. Nevertheless,

Mark D. Tomer is a research soil scientist at the USDA Agricultural Research Service National Laboratory for Agriculture and the Environment, Ames, lowa. 
a better understanding of how practices can be used in combination is needed to identify optimized water quality solutions.

However, these two monitoring approaches (watershed pairing and upstream-downstream comparison) can be combined experimentally to assess a sequence of two practices. That is, rather than using two gage records to assess a single practice, we use four gages to assess two practices and their interaction. This would provide greater return on the investment in conservation effects research. Further, data that provide details on practice effectiveness both alone and in combination could help advance model development by providing superior data for model calibration at small watershed scales.

\section{The Twice-Paired Watershed Experiment Design}

The twice-paired design (figure 1) would, like the traditional paired watershed experiment, include a pretreatment calibration period. However, the pretreatment period would begin by installing and monitoring a pair of edge-of-field practices, placed below two similarly managed fields. The example shown (figure 1) depicts a pair of denitrifying bio- reactors (Schipper et al. 2010), where inflows and outflows would be monitored. The first few years of data provide calibration of the hydrology and water quality between the two fields, and replicate data sets of inflows and outflows to evaluate the edge-of-field practice. The replication provides information on the consistency of performance by the edge-of-field practice and a side-by-side calibration for later determining interacting effects of two practices. After the calibration period, an in-field practice is installed within one of the two fields. As the treatment period monitoring progresses, comparing the relationship between the inflows to the edge-of-field pre- and posttreatment provides data to evaluate the in-field practice on its own. More specifically, the pre- and posttreatment inflow data sets provide data that are analyzed to identify significant differences between pre- and posttreatment periods. Also, the influence of the in-field practice on the edge-of-field practice's performance can be evaluated by determining whether/how the relationship between the paired edge-of-field practices is changed by implementing the in-field practice.

There are several approaches to statistically analyze data from paired watershed experiments. Pretreatment calibration data improves the statistical power of any approach (Loftis et al. 2001). Simple regression can be used to evaluate changes in runoff/nutrient-load responses to rainfall following treatment implementation (King et al.2008). Analysis of covariance approaches utilize multivariate data to separate effects of storm size and antecedent conditions from treatment responses (Bishop et al. 2005); this approach would be particularly valuable in those rare instances where watershed-scale treatments could be replicated. However, analysis of covariance is best applied to data from rainfall-runoff events, which can be considered independent observations. However, subsurface flows (tile discharge, baseflow) are continuous and serially correlated, in which case autoregressive terms should be included to compare the magnitude and timing of flows among watershed treatments (Tomer et al. 2005).

\section{The Possibility of Practice Synergies}

In-field and edge-of-field practices can have different types of impacts in terms of examining rainfall-runoff and runoff-nutrient load relationships. The way in which these impacts may interact determines the potential to

\section{Figure 1}

Concept for a twice-paired watershed experiment. Two edge-of-field practices are installed during the calibration period, then one in-field practice is installed during the treatment period. The watersheds and edge-of-field practices are calibrated during the first two to five years, followed by evaluation of the in-field practice. Any change in the relationship between treatment efficiencies of the paired edge-of-field practices between calibration and treatment periods determines synergies and/or tradeoffs of using the two practices in combination.

Paired watershed experiment (in field practice, edge-of-field monitoring)

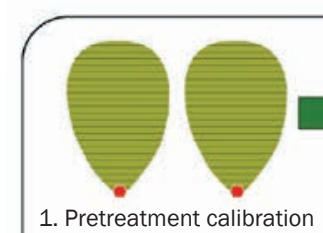
(2+ years)

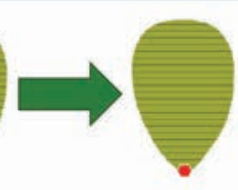

2. Treatment evaluation (3+ years)

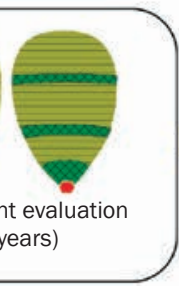

Upstream-downstream experiment (edge-of-field practice, edge-of-field monitoring; bioreactor as an example)

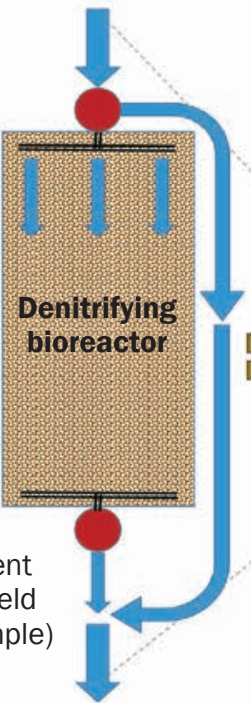

Twice-paired watershed experiment

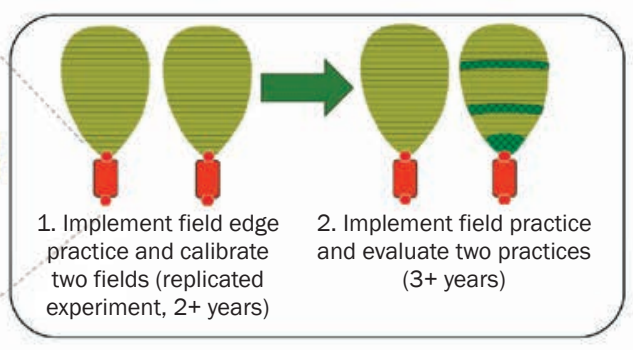




\section{Figure 2}

Examples of twice-paired watershed experiments, identified using the Agricultural Conservation Planning Framework. Edge-of-field/in-field treatment combinations shown are ( $a$ and $b$ ) nutrient removal wetlands/cover crops and ( $c$ and $d)$ denitrifying bioreactors/drainage water management.

(a)

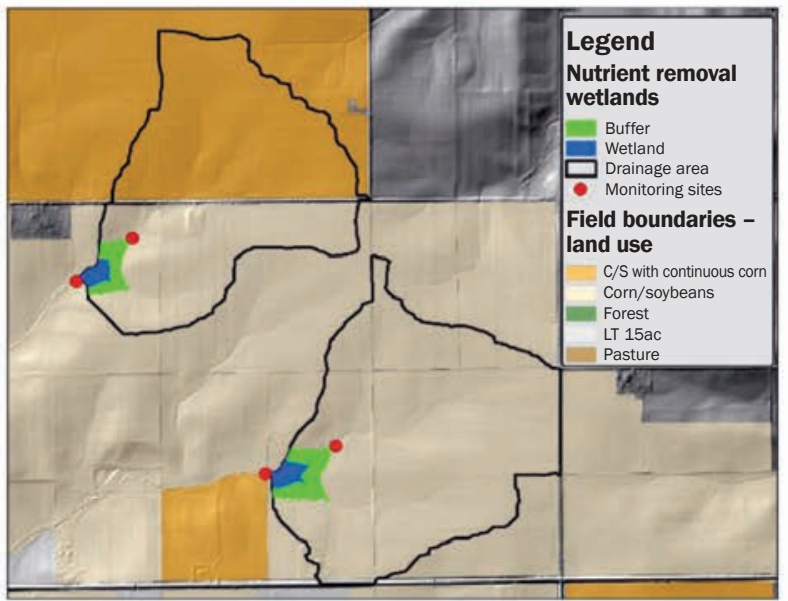

(c)

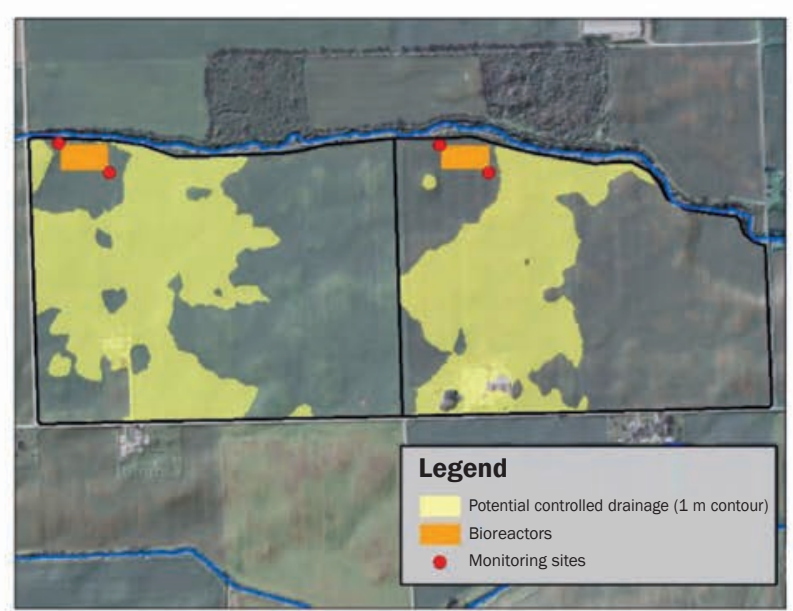

(b)

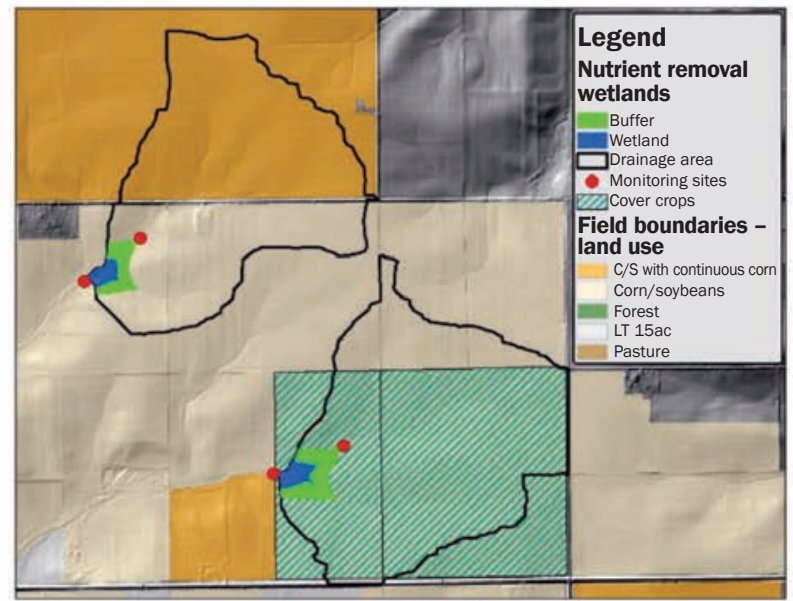

(d)

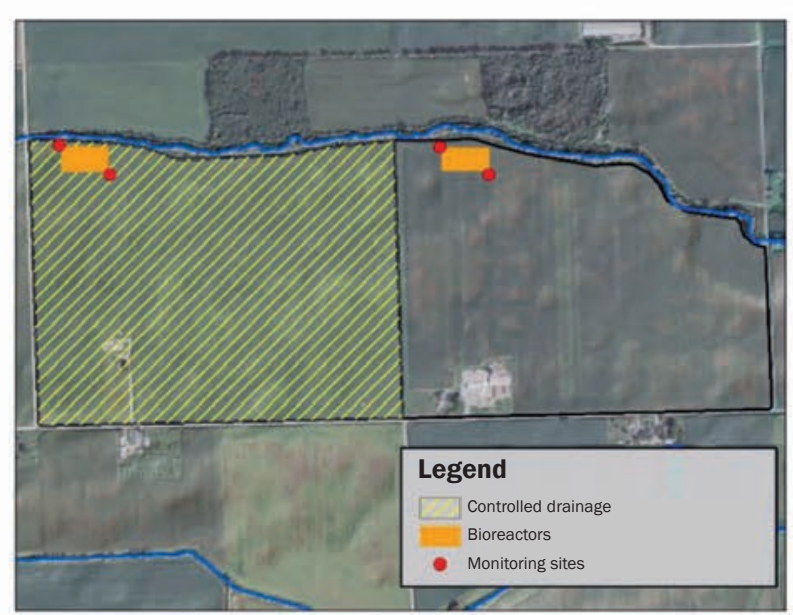

obtain synergistic water quality improvements through stacking of practices. A key benefit of in-field practices (e.g., reduced or no tillage and cover crops) is to reduce the runoff fraction by encouraging greater infiltration (Kaspar et al. 2001; Sun et al. 2015). This provides an opportunity to then increase (or synergize) the effectiveness of the edge-of-field practice. That is, because effectiveness of edge-of-field practices are usually determined by the residence time of runoff detention, lower runoff fractions from an infield practice deliver smaller runoff volumes to the field edge, which either provides a greater residence time and effectiveness to the edge-of-field practice, or allows the edgeof-field practice to be downsized, enabling a larger number of fields to be protected with a given conservation practice budget.
Where such combined practice effects can be demonstrated experimentally, agricultural water quality models could be tested for their capacity to simulate changes in the effectiveness of edge-of-field practices due to the presence/absence of in-field practices.

\section{Example Applications}

A variety of in-field and edge-of-field practice pairings can be tested using this experimental design. Two examples are illustrated using results of the Agricultural Conservation Planning Framework obtained from watersheds in Iowa (figure 2a) and Indiana (figure 2b). A pair of small nutrient removal wetlands could be located below adjacent cropped fields as shown in figure $2 \mathrm{a}$, which are sized at $<2 \%$ of the drainage area. Once both wetlands were installed, an initial calibration period would compare the relative performance of these two wetlands for nitrate $\left(\mathrm{NO}_{3}^{-}\right)$removal, followed by a treatment period in which the effectiveness of cover crops on $\mathrm{NO}_{3}^{-}$losses would be evaluated, both with and without the presence of the wetland practice. In the second example (figure $2 b$ ), a pair of denitrifying bioreactors could be installed to receive tile drainage from adjacent fields that are also flat enough to be suited for drainage water management. The two bioreactors would be installed to initiate the experiment, and the flow volumes and $\mathrm{NO}_{3}^{-}$loads from the fields, above and below the bioreactors (including high flows that bypass the bioreactors in both positions), would be monitored. Following the initial calibration period, drainage water management/water table control would 
be implemented in one of the two fields to monitor tile flows and $\mathrm{NO}_{3}^{-}$loads with neither, each, and both the in-field and edge-of-field practices during the treatment period. Controlled drainage can reduce drainage volumes, which would decrease the $\mathrm{N}$ load to the edge of the field and could increase relative bioreactor performance for $\mathrm{N}$ removal.

\section{Conclusion}

Our ability to reduce nutrient loads from agriculture may depend on our ability to use conservation practices in combination. Multiple practices can help account for water quality tradeoffs that are involved with practice selection, and can provide a "treatment train," or sequence of practices that detain and treat water flows along hydrologic pathways between each field in a watershed and the watershed's outlet (Tomer et al. 2015). If we are aware that combinations of practices will be necessary to meet nutrient reduction goals, then to apply this concept wisely we should obtain experimental data that reveal synergies and tradeoffs involved with using conservation practices in sequence, in a way that provides new knowledge targeted at conservation opportunities that are most numerous and can be best leveraged in given watersheds and landform regions. A twicepaired experimental design is proposed here to better determine how combinations of practices may provide the greatest environmental synergies, potentially leading to conservation programs more effective in improving water quality.

The twice-paired watershed experimental design is just an idea at this point. A demonstration is needed to confirm that an actual experiment can be implemented to obtain and analyze data to test this concept. Data on the soils, land use, and topography of a watershed can be used to identify which practices have the greatest number of implementation opportunities (Tomer et al. 2015), which can in turn be leveraged to identify the best (i.e., most extendible) practices to include in twicepaired experiments. After concept validation with actual measured data, a twice-paired experiment should provide information useful in improving watershed models by showing how synergies and tradeoffs involved with stacked practices can be simulated with watershed models. Then, applying watershed models to devise/test watershed conservation options could be done with greater confidence in actual planning contexts.

\section{References}

Ball Coehlo, B., D. Lapen, R. Murray, E. Topp, A. Bruin, and B. Khan. 2012. Nitrogen loading to offsite waters from liquid swine manure application under different drainage and tillage practices. Agricultural Water Management 104:40-50.

Bishop, P.L., W.D. Hively, J.R. Stedinger, M.R. Rafferty, J.L. Lojpersberger, and J.A. Bloomfield. 2005. Multivariate analysis of paired watershed data to evaluate agricultural best management practice effects on stream water phosphorus. Journal of Environmental Quality 34(3):1087-1101.

Brooks, E.S., S.M. Saia, J. Boll, L. Wetzel, Z.M. Easton, and T.S. Steenhuis. 2015. Assessing BMP effectiveness and guiding BMP planning using process-based modeling. Journal of the American Water Resources Association 51(2):343-358.

Gebremichael, L.T., T.L. Veith, and J.M. Hamlett. 2013 Integrated watershed- and farm-scale modeling framework for targeting critical source areas while maintaining farm economic viability. Journal of Environmental Management 114:381-394.

Hewlett, J.D. 1971. Comments on the catchment experiment to determine vegetal effects on water yield. Water Resources Bulletin 7(2):376-381

Kalcic, M.M., J. Frankenberger, and I. Chaubrey. 2015. Spatial optimization of six conservation practices using SWAT in tile-drained agricultural watersheds. Journal of the American Water Resources Association 51(4):956-972.

Karlen, D.L., D.L. Dinnes, M.D. Tomer, D.W. Meek, C.A. Cambardella, and T.B. Moorman. 2009. Is no-tillage enough? A field-scale watershed assessment of conservation effects. Electronic Journal of Integrative Biosciences 7(2):1-24.

Kaspar, T.C., J.K. Radke, and J.M. Laflen. 2001. Small grain cover crops and wheel traffic effects on infiltration, runoff, and erosion. Journal of Soil and Water Conservation 56(2):160-164.

King, K.W., P.C. Smiley, B.J. Baker, and N.R. Fausey. 2008. Validation of paired watersheds for assessing conservation practices in the Upper Big Walnut Creek watershed, Ohio. Journal of Soil and Water Conservation 63(6):380-395, doi:10.2489/ jswc.63.6.380.

Lazarus, W.F., D.J. Mulla, and D. Wall. 2014. A spreadsheet planning tool for assisting a state agency with cost effective watershed scale surface water nitrogen planning. Journal of Soil and Water Conservation 69(2):45A-50A, doi:10.2489/jswc.69.2.45A

Loftis, J.C., L.H. MacDonald, S. Streett, H.K. Iyer, and K. Bunte. 2001. Detecting cumulative watershed effects: The statistical power of pairing. Journal of Hydrology 251:49-64.
Osmond, D., D. Meals, D. Hoag, M. Arabi, A. Luloff., G. Jennings, M. McFarland, J. Spooner, A. Sharpley, and D. Line. 2012. Improving conservation practices programming to protect water quality in agricultural watersheds: Lessons learned from the National Institute of Food and Agriculture-Conservation Effects Assessment Project. Journal of Soil and Water Conservation 67(5):122A-127A, doi:10.2489/ jswc.67.5.122A

Reba, M.L., M. Daniels, Y. Chen, A. Sharpley, J. Bouldin, T. Gray Teague, P. Daniel, and C.G. Henry. 2013. A statewide network for monitoring agricultural water quality and water quantity in Arkansas. Journal of Soil and Water Conservation 68(2):45A-49A, doi:10.2489/ jswc.68.2.45A.

Rissman, A.R., and S.R. Carpenter. 2015. Progress on nonpoint pollution: Barriers and opportunities. Daedalus 144(3):35-47.

Schipper, L.A., W.D. Robertson, A.J. Gold, D.B. Jaynes, and S.C. Camerson. 2010. Denitrifying bioreactors - An approach for reducing nitrate loads to receiving waters. Ecological Engineering 36(11):1532-1543.

Sharpley, A.N., L. Bergström, H. Aronsson, M. Bechmann, C.H. Bolster, K. Börling, F. Djodjic, H.P. Jarvie, O.F Schoumans, C. Stamm, K.S. Tonderski, B. Ulen, R. Uusitalo, and P.J.A. Withers. 2015. Future agriculture with minimized phosphorus losses to waters: Research needs and direction. Ambio 44(S2):S163-S179.

Smith, D.R., W. Francesconi, S.J. Livingston, and C. Huang. 2015. Phosphorus losses from monitored fields with conservation practices in the Lake Erie Basin, USA. Ambio 44(S2):S319-S331.

Sun, Y., Y. Zeng, Q. Shi, X. Pan, and S. Huang. 2015 No-tillage controls on runoff: A meta-analysis. Soil and Tillage Research 153:1-6.

Tomer, M.D., D.W. Meek, and L.A. Kramer. 2005. Agricultural practices influence flow regimes of headwater streams in western Iowa. Journal of Environmental Quality 34(5):1547-1558.

Tomer, M.D., T.B. Moorman, J.L. Kovar, K.J. Cole, and D.J. Nichols. 2016. Eleven years of runoff and phosphorus losses from two fields with and without manure application, Iowa, USA. Agricultural Water Management 168:104-111.

Tomer, M.D., S.A. Porter, K.M.B. Boomer, D.E. James, J.A. Kostel, M.J. Helmers, T.M. Isenhart, and E. McLellan. 2015. Agricultural Conservation Planning Framework: 1. Developing multi-practice watershed planning scenarios and assessing nutrient reduction potential. Journal of Environmental Quality 44(3):754-767.

Yang, G., and E.P.H. Best. 2015. Spatial optimization of watershed management practices for nitrogen load reduction using a modeling-optimization framework. Journal of Environmental Management 161:252-260. 